\title{
Effect of glacial-interglacial sea-level changes on the displacement and stress field in the forearc and along the plate interface of subduction zones
}

\author{
T. Li and A. Hampel \\ Institut für Geologie, Leibniz-Universität Hannover, Callinstr. 30, 30167 Hannover, Germany \\ Correspondence to: T. Li (li@geowi.uni-hannover.de)
}

Received: 7 December 2011 - Published in Solid Earth Discuss.: 21 December 2011

Revised: 3 February 2012 - Accepted: 4 February 2012 - Published: 22 February 2012

\begin{abstract}
Combined seismological, space-geodetic and numerical studies have shown that the seismicity at subduction zones may be modulated by tides and glacier fluctuations on timescales of 1-100 a, because these changes in loads on Earth's surface are able to alter the stress field in the upper plate and along the plate interface. Here we use a two-dimensional finite-element model of a subduction zone to investigate how glacial-interglacial sea-level changes affect the forearc region and the plate interface. The model results show that a sea-level fall by $125 \mathrm{~m}$ over 100 ka causes up to $0.7 \mathrm{~m}$ of vertical displacement, with the maximum uplift occurring between the trench and the coast. The uplift signal induced by the sea-level fall decreases to zero $\sim 20 \mathrm{~km}$ landward of the coastline. A subsequent sea-level rise by $125 \mathrm{~m}$ over $20 \mathrm{ka}$ causes subsidence, which is again most pronounced in the submarine part of the forearc. The sealevel changes cause horizontal displacements of up to $0.12 \mathrm{~m}$, which are directed seaward during sea-level fall and landward during sea-level rise. With respect to the stress field, the sea-level changes lead to variations in the vertical stress and the shear stress of up to $1.23 \mathrm{MPa}$ and $0.4 \mathrm{MPa}$, respectively. The shear stress variations are highest beneath the coast, i.e. in the area where the sea-level changes cause the strongest flexure. The resulting Coulomb stress changes on the plate interface are of the order of $0.2-0.5 \mathrm{MPa}$ and indicate that earthquakes are promoted during sea-level fall and delayed during sea-level rise. Our findings imply that eustatic sea-level changes during glacial-interglacial periods may have induced displacements and stress changes that were large enough to affect the seismic cycle of subduction thrusts.
\end{abstract}

\section{Introduction}

Active faulting in subduction zones poses a serious seismic threat to the often densely populated coastal regions. As a consequence, much effort has been put into monitoring the seismicity beneath the forearc and the identification of parameters that may modulate the frequency and magnitude of earthquakes on different timescales. One of the first parameters that were recognized to affect the seismicity in subduction zones was the ocean tides. The hypothesis of ocean tides as a trigger of earthquakes was put forward by Nasu et al. (1931) after an earthquake hit central Japan in 1930. Since then, a positive correlation between ocean tides and earthquake occurrences has been documented by many studies (e.g. Shlien, 1972; Tsuruoka et al., 1995; Kasahara, 2002; Cochran et al., 2004). After statistically analysing 988 globally distributed high-magnitude seismic events, Tsuruoka et al. (1995) concluded that, of all fault types, normal faults are most susceptible to tidally triggered earthquakes because the periodic ocean loading affects the vertically oriented maximum principal stress. Based on the analysis of earthquake data from 1977-2000, Cochran et al. (2004) later showed that strong ocean tides can also trigger shallow thrust earthquakes, with the rate of earthquakes differing from the background rate by a factor of 3 with the tidal stress. They concluded that the tidal stress changes have more effect on thrust and normal faults than on strike-slip faults because the latter are oriented mostly subvertical and hence less susceptible to the variable ocean loading.

On the timescale of decades, the seismicity in subduction zones is influenced by fluctuations in the mass of 
glaciers situated in the upper plate (e.g. Cohen, 1993; Sauber et al., 2000; Ivins and James, 2004). A combination of glaciological and seismological records, modern spacegeodetic measurements and numerical modelling revealed that glacier mass fluctuations over the last 10-100 years in south-central Alaska induced considerable vertical displacements and stress changes that have modulated the background seismicity of the subduction zone (Cohen, 1993; Sauber et al., 2000; Sauber and Molina, 2004). For example, in the eastern Chugach Mountains, southern Alaska, a largescale redistribution of glacier ice between 1993 and 1995 was associated with a significant increase in the number and size of earthquakes (Sauber et al., 2000). This finding was later confirmed by a comprehensive compilation of seismological and glaciological data for southern Alaska, which showed that rapid ice fluctuations promoted small earthquakes on thrust faults (Sauber and Ruppert, 2008).

On the timescale of 10-100 ka, eustatic sea-level changes may affect the stress state of the crust at the borders of ocean basins. During the last glacial-interglacial cycle that culminated in the Last Glacial Maximum (LGM) $\sim 20 \mathrm{ka}$ ago, the sea-level fall and subsequent rise was $\sim 125 \mathrm{~m}$ (Imbrie et al., 1984; Zachos et al., 2001; Peltier and Fairbanks, 2006). Using a semi-analytical approach with an elastic plate overlying a viscoelastic half-space, Luttrell and Sandwell (2010) showed that the post-LGM sea-level rise and the resulting flexural loading caused considerable stress perturbations in coastal regions worldwide. To estimate the effect of these stress perturbations on major plate boundary faults, which were not included in their model, they calculated the resolved shear and normal stresses for selected faults of known orientation. The results show that the post-LGM sea-level rise should have caused an increase in the Coulomb stress by up to $1.5 \mathrm{MPa}$ on the vertically oriented San Andreas, Alpine and North Anatolian faults (Luttrell and Smith, 2010). For the Cascadia subduction zone, which they approximated by a $15^{\circ}$-dipping plane, they calculated a change in the Coulomb stress of $\sim 0.4 \mathrm{MPa}$, using a friction coefficient of 0.4.

The results of the previous studies summarized above provide strong evidence that faults in the upper part of a subduction zone - including the seismogenic part of the plate interface - are susceptible to changes in ice and water loads on different timescales. So far, however, the effect of eustatic sea-level changes on uplift and subsidence of the forearc as well as on the stress along the plate interface remains unresolved. In this study, we use a two-dimensional numerical model with a subduction-zone geometry to quantify how the forearc and the plate interface respond to the sea-level fall and rise during a glacial-interglacial period. In the following, we describe the model setup and present the results with a focus on the induced changes in the displacement and stress fields in the upper part of the subduction zone, including the seismogenic part of the plate interface. Finally, we discuss implications for the seismic cycle of subduction thrusts.

\section{Model setup}

To quantify the effect of sea-level changes on a subduction zone, we use a two-dimensional finite-element model created with the commercial software ABAQUS (version 6.11). The model consists of a $1500 \mathrm{~km}$-long oceanic plate, which is subdivided into a $8 \mathrm{~km}$-thick crust and a $72 \mathrm{~km}$-thick lithospheric mantle, and a $1000 \mathrm{~km}$-long continental plate consisting of a $15 \mathrm{~km}$-thick upper crust, a $15 \mathrm{~km}$-thick lower crust and a $70 \mathrm{~km}$-thick lithospheric mantle. Our model does not include the sub-lithospheric mantle, i.e. we assume that glacial-interglacial sea-level changes do not induce significant viscous flow in the sub-lithospheric mantle. The model domain is meshed using triangular plane-strain elements with a maximum edge length of $1 \mathrm{~km}$. The rheological parameters of the model are given in Fig. 1. To obtain the geometry of a subduction zone as depicted in Fig. 1a, we perform the following steps: First, the initially horizontal oceanic plate is downflexed to take into account the bending stresses in the subducting plate (cf. Buiter et al., 2001; Hampel and Pfiffner, 2006). This model step is carried out using a viscosity of $1 \times 10^{23} \mathrm{Pas}$ for the lithospheric mantle. Afterwards, the continental plate is added to the model domain with the contact between the two plates representing the plate interface. In the same model step, a water body and a pressure (Fig. 1a), which together represent an ocean with a average water depth of $5000 \mathrm{~m}$, are added on top of the oceanic plate and the continental margin. At the trench, the water depth increases to $6580 \mathrm{~m}$. In the third model step, isostatic equilibrium is established. This model step as well as the following steps is computed as a static analysis, i.e. viscous deformation is not considered. As the displacements and stress changes resulting from the sea-level variations occur in the uppermost part of the model and are small compared to the thickness of the plates, the two vertical model sides and the bottom are fixed in the vertical and horizontal directions to facilitate the calculation of the model.

During the final model step, the falling and subsequently rising sea level during a glacial-interglacial cycle is simulated by changing the pressure applied on top of the water body. Based on the global sea-level curve derived from the oxygen-isotope record (Imbrie et al., 1984; Chappell and Shackleton, 1986; Zachos et al., 2001; Peltier and Fairbanks, 2006), we assume a sea-level fall by $125 \mathrm{~m}$ over $100 \mathrm{ka}$ and a subsequent sea-level rise by the same amount over $20 \mathrm{ka}$ (Fig. 1b). During these sea-level changes the plate interface is kept locked, i.e. no relative displacement occurs between the two plates. For comparison, we also calculated a reference model run, in which no sea-level changes occur.

\section{Model results}

To analyse the effect of the sea-level fall and rise on the upper part of the subduction zone, we extracted the changes in the vertical and horizontal displacement as well as in the 


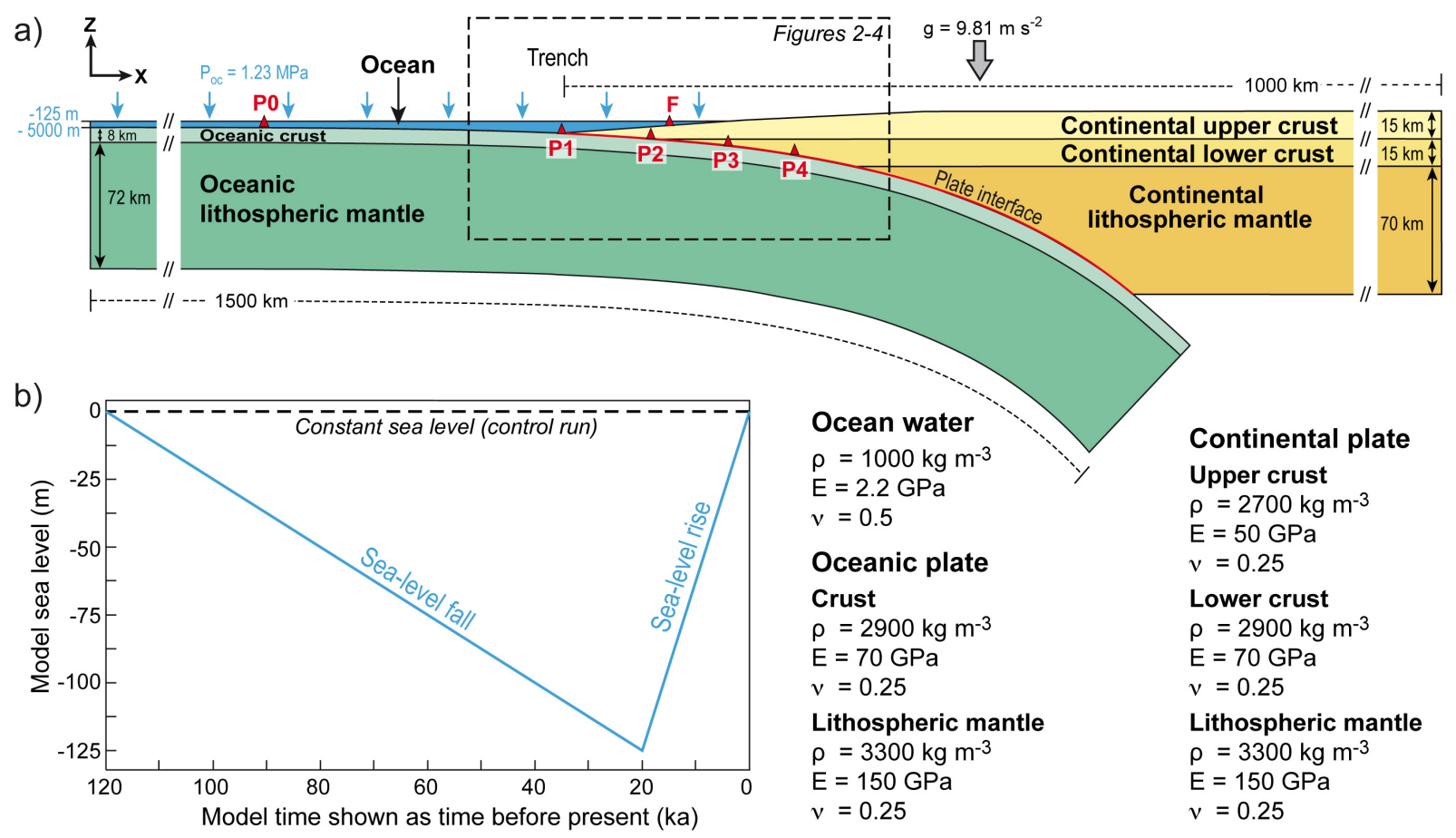

Fig. 1. (a) Setup of the finite-element model with an oceanic and a continental plate that are in contact along a locked plate interface (solid red line). Rheological parameters are $\rho$ density, $E$ Young's modulus, and $v$ Poisson's ratio. Gravity is included as a body force ( $g$ acceleration of gravity). An ocean on top of the oceanic plate and the continental margin with an average water depth of $5000 \mathrm{~m}$ is implemented as a combination of a water body (average water depth: $4875 \mathrm{~m}$ ) and a pressure $\mathrm{P}_{\mathrm{Oc}}$ equivalent to $125 \mathrm{~m}$ of water (blue arrows). This pressure is decreased and subsequently increased to simulate the falling and subsequently rising sea level during a glacial-interglacial cycle, respectively (see Fig. $1 \mathrm{~b}$ for the temporal evolution of the pressure). At the beginning of the model run, isostatic equilibrium is established by a lithostatic pressure and elastic foundation at the bottom of the model. Afterwards, the model sides and bottom are fixed in the horizontal and vertical directions (see text for details). Red triangles mark the locations of points F and P0-P4, at which displacements and stresses were extracted from the model (Figs. 2-4, 6). Box with dashed outline marks the part of the model for which the displacement and vertical stress fields are shown in Figs. 2-4. (b) Temporal evolution of the sea level in the model, reflecting a fall and subsequent rise by $125 \mathrm{~m}$ over $120 \mathrm{ka}$ (cf. Imbrie et al., 1984; Peltier and Fairbanks, 2006). For comparison, a control run was performed with a constant sea level (dashed line).

stress field from the model. In addition to cross-sections of the model, the evolution of these parameters through time will also be shown at six selected points, with point $\mathrm{F}$ being located in the submarine part of the forearc, four points (P1P4) located on the plate interface and one point positioned $360 \mathrm{~km}$ seaward of the trench (P0) (see Fig. 1a). Note that the model time is shown as time before present in all subsequent figures.

\subsection{Vertical displacement}

During the sea-level fall between $120 \mathrm{ka}$ and $20 \mathrm{ka}$, the upper part of the subduction zone rises by up to $0.7 \mathrm{~m}$ (Fig. 2a), with the uplift maximum occurring in the forearc region at point $F$. The displacement induced by the sea-level fall decreases both with depth and landward where it diminishes to zero $\sim 20 \mathrm{~km}$ landward of the coast. During the subsequent sea-level rise between $20 \mathrm{ka}$ and $0 \mathrm{ka}$, the forearc and the oceanic plate subside by up to $0.7 \mathrm{~m}$ owing to the increase in the water load (Fig. 2b). The temporal evolution of the ver- tical displacement at points $\mathrm{P} 0-\mathrm{P} 4$ (Fig. 2c) shows that the points located closest to the ocean floor (P0-P2) experience the strongest uplift and subsidence, whereas points P3 and P4 located at a depth of $15 \mathrm{~km}$ and $20 \mathrm{~km}$, respectively, are barely affected by the sea-level changes. In the control run without sea-level changes, no vertical displacement occurs.

\subsection{Horizontal displacement}

The horizontal displacement (Fig. 3) induced by the sea-level changes reaches a maximum value of $0.12 \mathrm{~m}$. The highest horizontal displacements occur in the submarine part of the forearc, beneath the coastline in the vicinity of the plate interface and in the oceanic lithospheric mantle. During the sea-level fall, the horizontal displacement is directed seaward (Fig. 3a), whereas landward movements occur during the sea-level rise (Fig. 3b). Along the plate interface, the highest horizontal displacement occurs at point P3 (Fig. 3a,b). This implies that the distance between $\mathrm{P} 3$ and $\mathrm{P} 1$ decreases during the sea-level fall, whereas it increases during the sea-level 

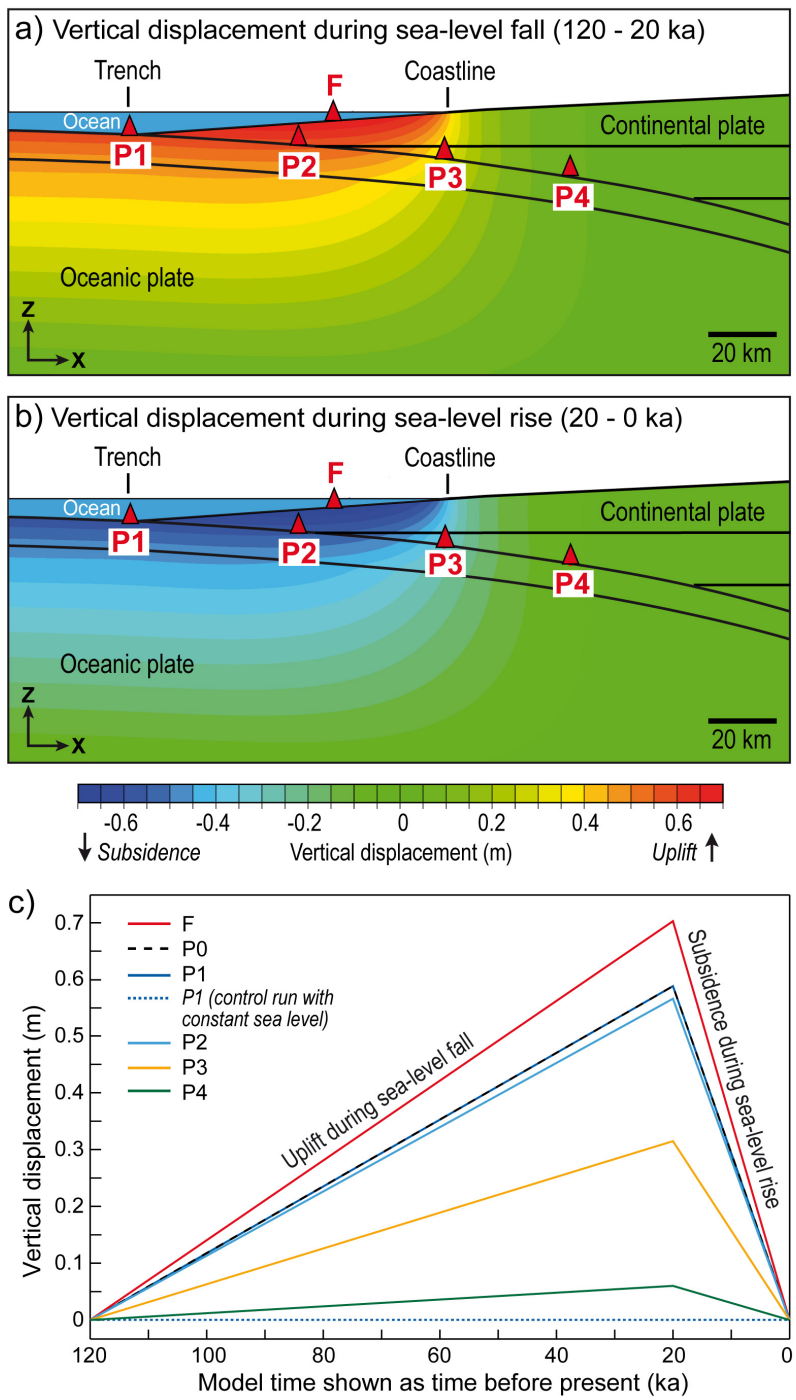

Fig. 2. Vertical displacement induced by (a) a falling sea level (120$20 \mathrm{ka})$ and (b) a rising sea level (20-0 ka). (c) Temporal evolution of the vertical displacements at point $\mathrm{F}$ in the forearc and at points $\mathrm{P} 0-\mathrm{P} 4$ located on the plate interface (Figs. 1a, 2a). For reference, the result from the control run (constant sea level) is shown for point P1.

rise. In contrast, the distance between $\mathrm{P} 3$ and $\mathrm{P} 4$ increases during the sea-level fall and decreases during the sea-level rise.

\subsection{Stress changes}

To illustrate the effect of the sea-level variations on the stress field, we extracted the changes in the vertical stress $\sigma_{\mathrm{z}}$, the horizontal stress $\sigma_{\mathrm{x}}$ and the shear stress $\tau_{\mathrm{xz}}$ between 120 and $20 \mathrm{ka}$ (sea-level fall) and from 20 to $0 \mathrm{ka}$ (sea-level rise) (Fig. 4). In concert with the changing water load, the vertical stress decreases during sea-level fall and increases during
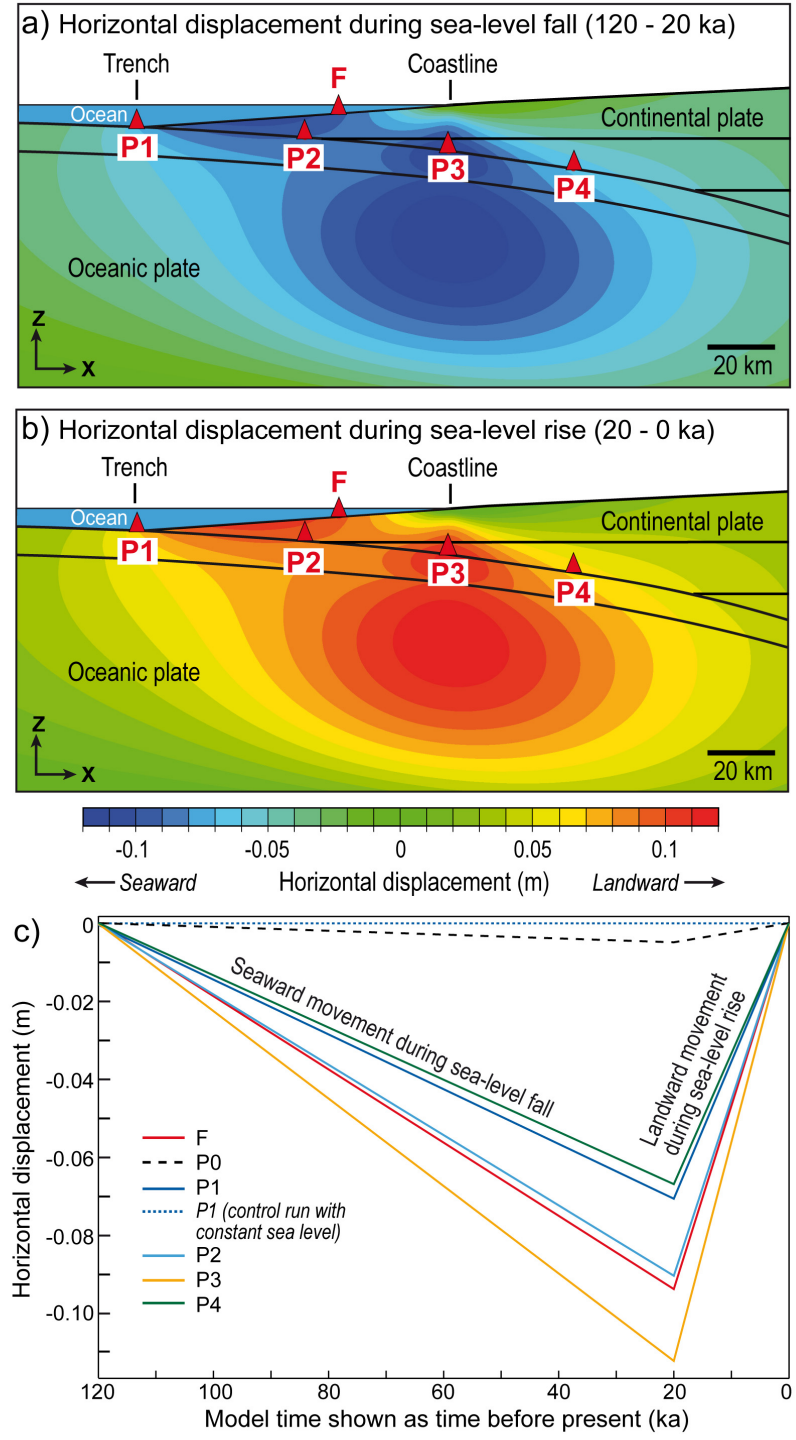

Fig. 3. Horizontal displacement induced by (a) a falling sea level (120-20 ka) and (b) a rising sea level (20-0 ka). (c) Temporal evolution of the horizontal displacements at point $\mathrm{F}$ in the forearc and at points $\mathrm{P} 0-\mathrm{P} 4$ located on the plate interface (Figs. 1a, 3a). For reference, the result from the control run (constant sea level) is shown for point P1.

sea-level rise. The vertical stress changes have a maximum value of $1.23 \mathrm{MPa}$, which is equal to the magnitude of the applied water load, and primarily affect the region seaward of the coastline (Fig. 4a, b). Changes in the horizontal stress reach a maximum value of $0.75 \mathrm{MPa}$ and are most pronounced in the submarine part of the forearc and on the plate interface in the vicinity of point P2 (Fig. 4c, d). In contrast to the vertical and horizontal stress, the shear stress increases during the sea-level fall, i.e. when the model region seaward of the coastline rises relative to the region landward of the coastline (Fig. 2a), and decreases during the sea-level rise. 
During sea-level fall (120 - $20 \mathrm{ka})$
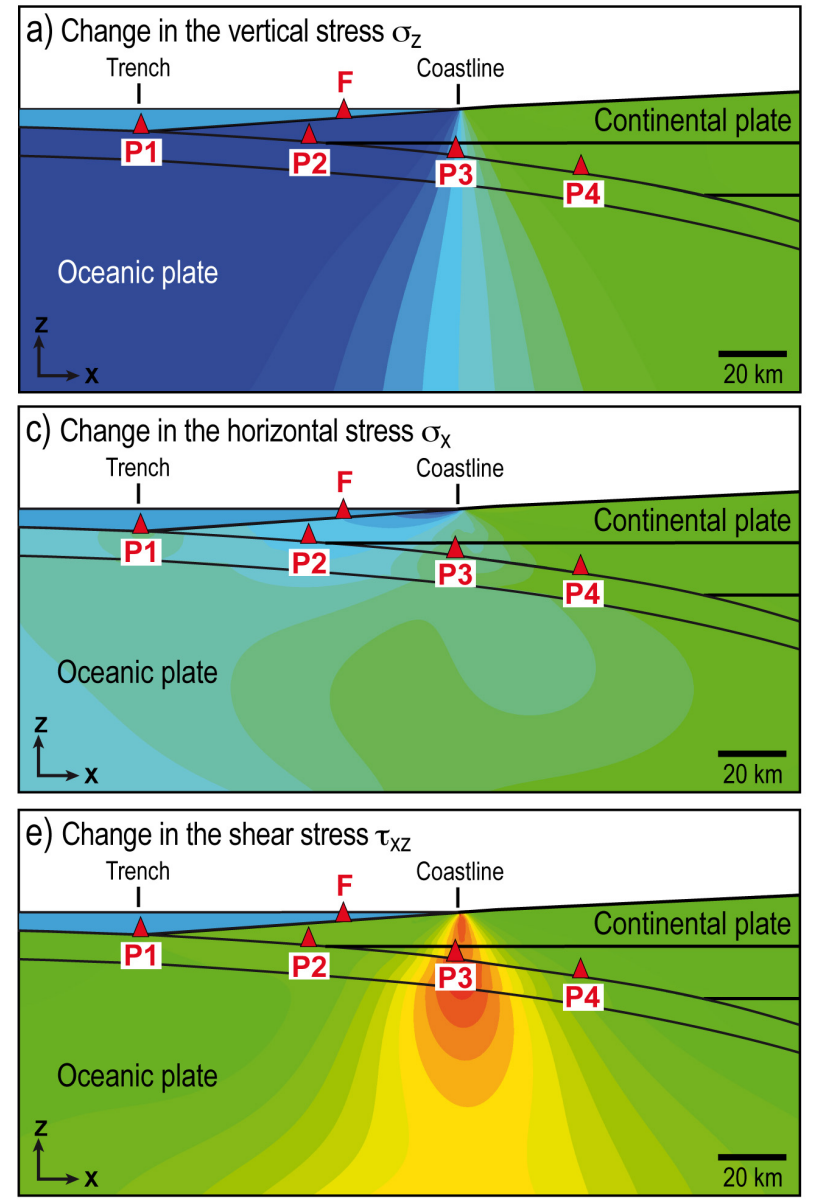

During sea-level rise (20 - $0 \mathrm{ka})$
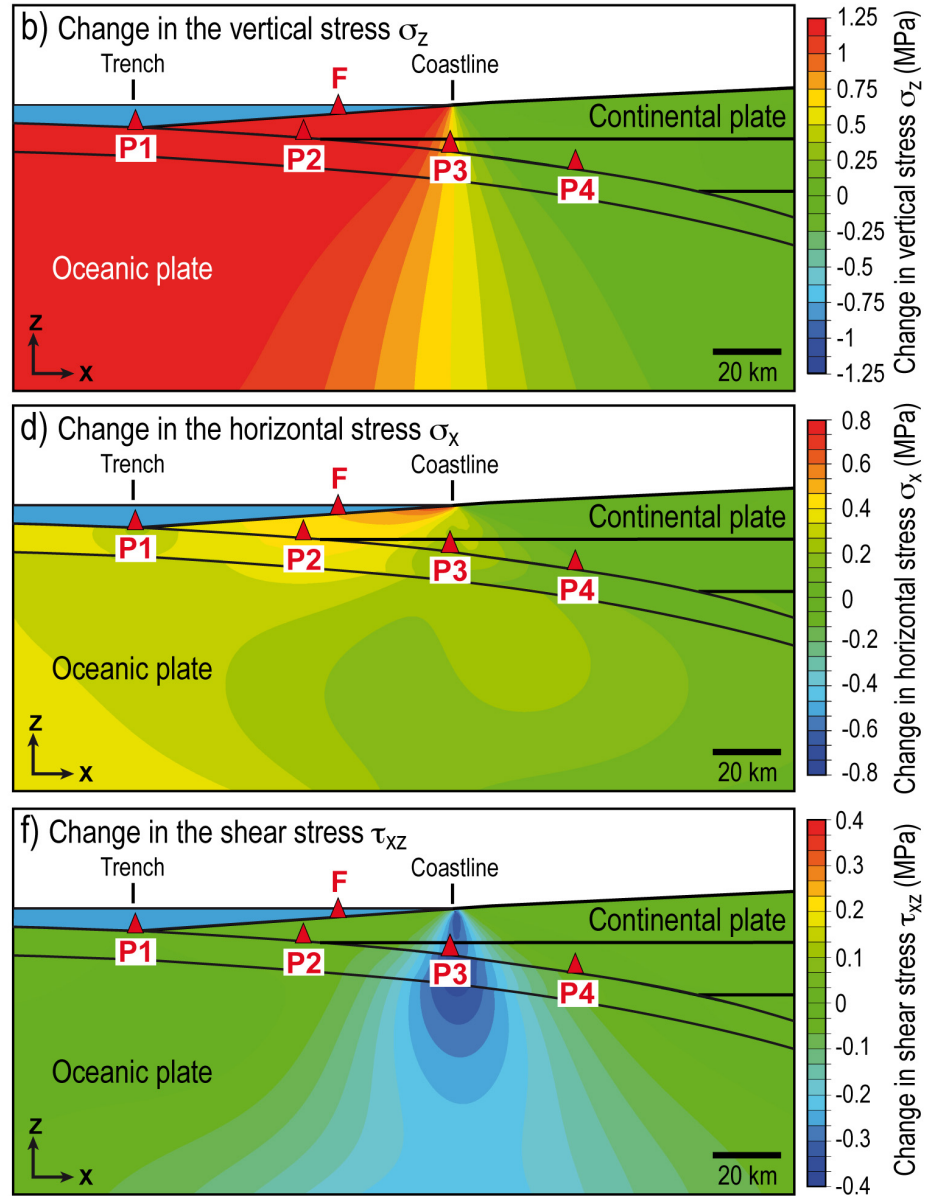

Fig. 4. Stress variations caused by the sea-level changes. Left column shows the change in (a) the vertical stress $\sigma_{\mathrm{Z}}$, (b) horizontal stress $\sigma_{\mathrm{X}}$ and (c) shear stress $\tau_{\mathrm{xz}}$ during sea-level fall (120-20 ka). Right column shows the change in (b) the vertical stress $\sigma_{\mathrm{Z}}$, (d) horizontal stress $\sigma_{\mathrm{X}}$ and (f) shear stress $\tau_{\mathrm{xz}}$ during sea-level rise (20-0 ka).

The shear stress change $\tau_{\mathrm{xz}}$ is highest $(0.4 \mathrm{MPa})$ beneath the coastline and in the vicinity of point $\mathrm{P} 3$ (Fig. 4e, f), i.e. in the area that experiences the strongest flexural unbending and subsequent bending in response to the changing water load.

\section{Discussion and conclusions}

Our model results indicate that sea-level changes during glacial-interglacial cycles affect the displacement and stress field in the forearc, along the plate interface, and in the upper part of the downgoing oceanic plate. During a fall of the sea level, uplift and seaward movements prevail (Fig. 5a); during sea-level rise, subsidence and landward movements occur (Fig. 5b). The vertical displacements reach the highest values (up to $0.7 \mathrm{~m}$ ) in the upper $10-15 \mathrm{~km}$ of the two plates and decrease rapidly with depth (Fig. 2). Although the horizontal displacements are relatively small (up to $0.12 \mathrm{~m}$ ), the region that is affected is larger and located in the forearc beneath the coastline (Fig. 3). In our model, we used a simplified sealevel curve with a linear rise of the sea level over $20 \mathrm{ka}$, which results in maximum rates of vertical and horizontal displacements of $0.035 \mathrm{~m} \mathrm{ka}^{-1}$ and $0.006 \mathrm{~m} \mathrm{ka}^{-1}$, respectively. Taking into account geological evidence indicating that the post-LGM sea-level rise occurred mainly between 15 and $5 \mathrm{ka}$ at a rate of $\sim 12 \mathrm{~m} \mathrm{ka}^{-1}$ (e.g. Peltier and Fairbanks, 2006), this increases the rates of subsidence and landward movement by a factor of two, respectively. For short time intervals in the late Pleistocene, the rate of sea-level rise even reached maximum values of $\sim 30 \mathrm{~m} \mathrm{ka}^{-1}$, as shown by U/Th dating of corals (Bard et al., 1990). An additional factor that may further enhance the postglacial subsidence of the forearc and the oceanic plate is the transport of sediments from the continent to the ocean and their deposition in the forearc region and the trench. After glacial periods, the 

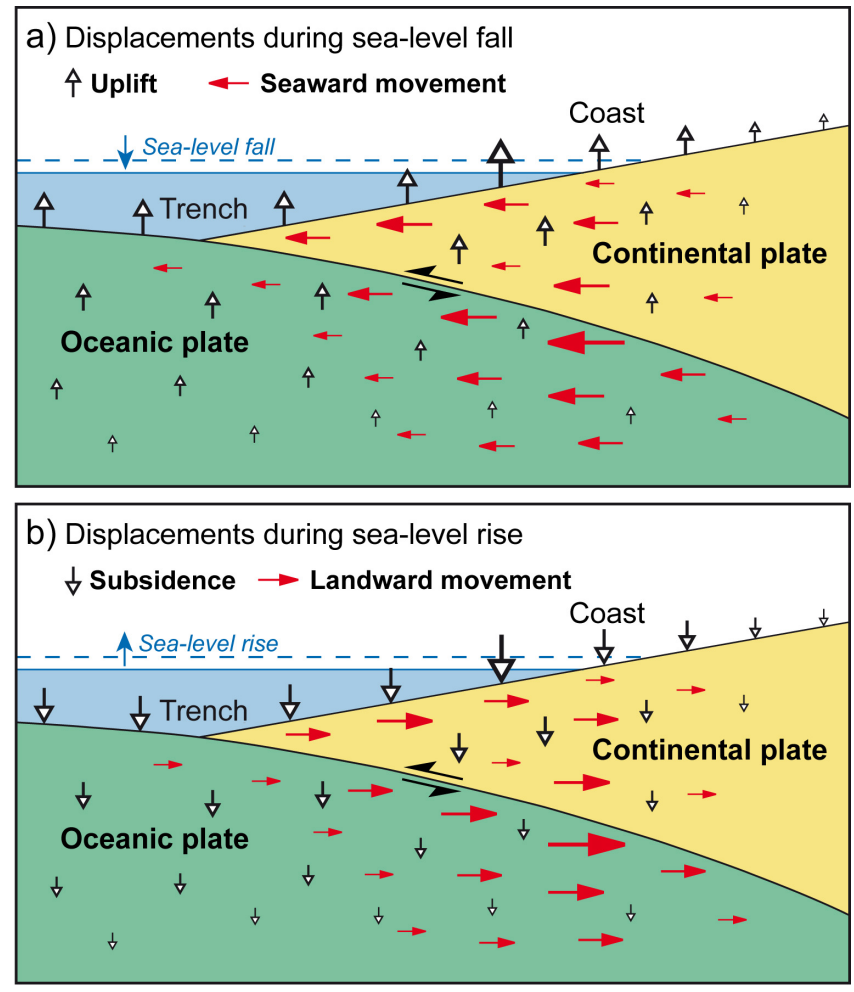

Fig. 5. Sketch summarizing the vertical and horizontal displacements resulting from (a) a falling sea level and (b) a rising sea level (not to scale).

rates of sediment transport and deposition in the oceans have increased considerably (e.g. Church and Slaymaker, 1989; Hebbeln et al., 2007; Covault et al., 2011). The additional loading by sediments would further increase the flexure induced by the rising sea level. As shown by studies of the Cascadia and Chilean convergent margins, the postglacial sediment input was probably high enough to affect the style of deformation in the accretionary prisms (Bourgois et al., 2000; Adam et al., 2004).

The displacements caused by unloading and subsequent loading of the oceanic plate and the forearc are associated with changes of the vertical and horizontal stresses (Fig. 4). In the region seaward of the coastline, the vertical stress change is equivalent to the change in the water load and affects the entire lithosphere. It diminishes in a narrow transition zone underneath the coast (Fig. 4a, b). The spatial distribution of the vertical stress indicates that the area beneath the coastline experiences the strongest flexure, which is also reflected in the spatial distribution of the shear stress that is focussed in a bell-shaped area beneath the coast (Fig. 4e, f). Our finding that the region below the coast experiences the strongest variations of vertical and shear stress is consistent with the results from semi-analytical flexural modelling (Luttrell and Sandwell, 2010), which showed that the flexural stresses induced by eustatic sea-level variations are highest near the coast. In contrast to the study by Luttrell and Sandwell (2010), who approximated the Cascadia subduction thrust by a plane of constant dip, our model setup allows us to analyse the spatial variations in displacement and stress along the convex contact between the bended oceanic plate and the continental plate. The results of this analysis are shown in Fig. 6 for a profile along the plate interface between the trench, i.e. point P1, and point P4 located at a depth of $\sim 20 \mathrm{~km}$. With respect to the vertical displacement, the profile shows that the sea-level changes cause uplift or subsidence of $0.58 \mathrm{~m}$ in the shallow part of the plate interface (Fig. 6a). The vertical displacement decreases to almost zero at point P4. In contrast, the horizontal displacement reaches the highest values $\sim 30 \mathrm{~km}$ landward of the trench and near point P3 (Fig. 6b). During the sea-level fall, the resolved normal stress on the plate interface decreases by up to 1.2 MPa beneath the submarine part of the forearc, i.e. in the shallow part of the plate interface, whereas it increases during the sea-level rise (Fig. 6c). Similar to the vertical displacement, the changes in normal stress diminish toward point $\mathrm{P} 4$. The change in the resolved shear stress on the plate interface has a peak beneath the coastline, where it reaches a value of $0.32 \mathrm{MPa}$ at a depth of $\sim 15 \mathrm{~km}$ (Fig. 6d). Beneath most of the submarine forearc, the change in shear stress is $\sim 0.1 \mathrm{MPa}$.

The part of the plate interface that experiences the most pronounced displacements and stress changes in the model coincides, in nature, with the upper portion of the seismogenic plate interface, which typically extends from a depth of a few kilometers to 30-50 km depth (Hyndman and Wang, 1995; Stern, 2002). As coseismic stress drops on inter-plate faults have been inferred to be of the order of 0.01-10 MPa (Kanamori and Anderson, 1975; Hanks, 1977; Scholz, 2002), the stress changes induced by sea-level variations may ultimately be able to promote or delay earthquakes in subduction zones. To evaluate the impact of the sea-level variations on the plate interface in more detail, we calculated the change in the Coulomb stress $\Delta \mathrm{C}=\Delta \tau-\mu \Delta \sigma_{\mathrm{n}}$, with $\Delta \tau$ being the shear stress change, $\mu$ the friction coefficient and $\Delta \sigma_{\mathrm{n}}$ the normal stress change. For the friction coefficient we used values of $0.1,0.2$ and 0.3 , respectively. The results show that sea-level fall increases the Coulomb stress on the plate interface between points P1 and P4 (Fig. 6e), which implies that earthquakes are promoted by a falling sea level. The highest increase in Coulomb stress occurs beneath the coastline, where it reaches a value of $0.55 \mathrm{MPa}$ for a friction coefficient of $\mu=0.3$ and $0.4 \mathrm{MPa}$ for $\mu=0.1$. Beneath the submarine forearc, the Coulomb stress is increased by $0.46 \mathrm{MPa}$ for $\mu=0.3$ and $0.22 \mathrm{MPa}$ for $\mu=0.1$, respectively. In contrast, a sea-level rise reduces the Coulomb stress (Fig. 6f), with the minimum values occurring beneath the coast. This implies that the occurrence of earthquakes is delayed during a rising sea level. 

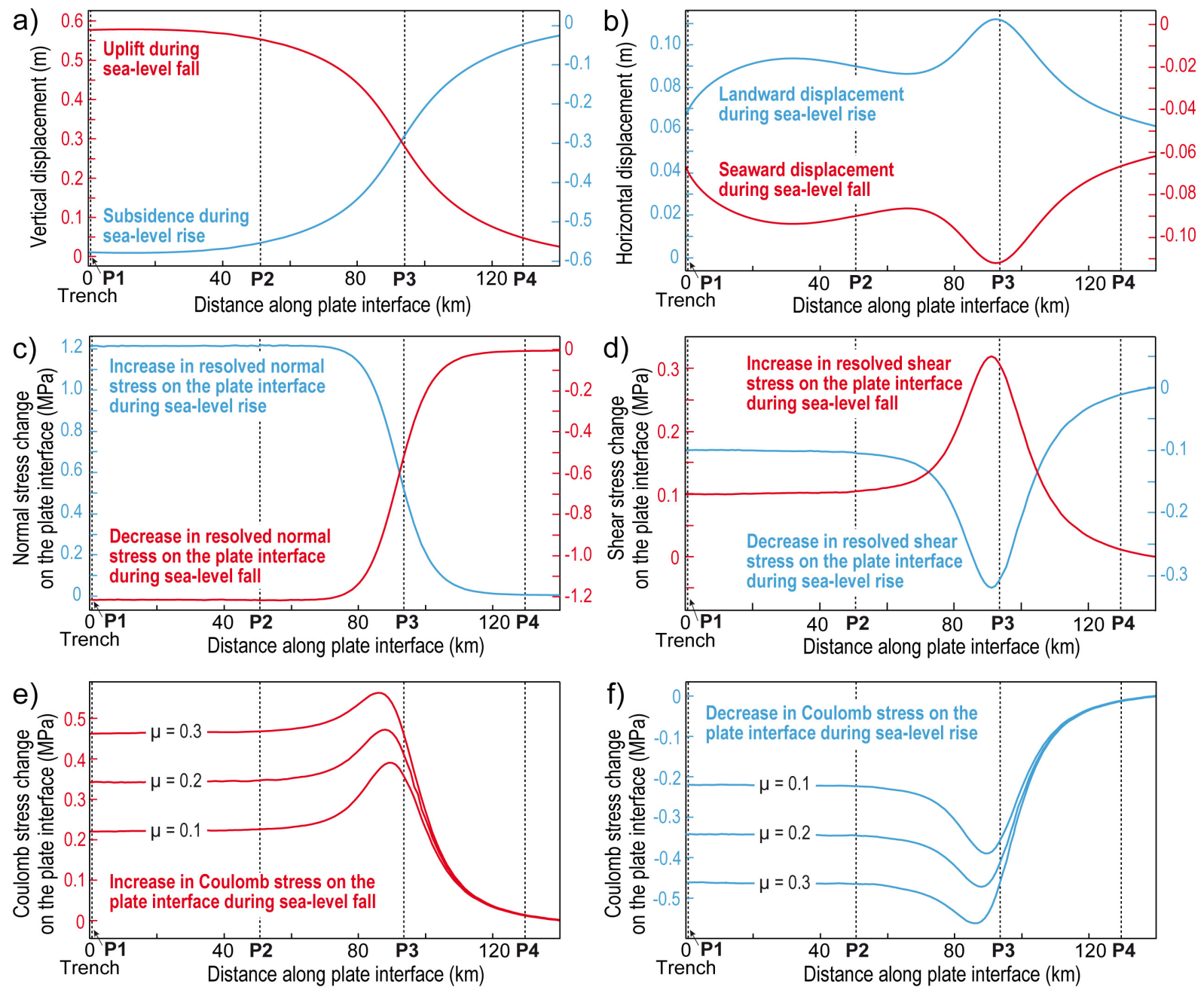

Fig. 6. Profiles along the plate interface showing displacement and stress changes induced by sea-level fall (red curves and scales) and sea-level rise (blue curves and scales). (a) Vertical displacement, (b) horizontal displacement, (c) resolved normal stress on plate interface and (d) resolved shear stress on plate interface. Changes in the Coulomb stress (e) during sea-level fall and (f) during sea-level rise were calculated using different values $(0.1,0.2$ and 0.3$)$ for the friction coefficient $\mu$. For location of points P1-P4 see Fig. 1a.

The promotion of earthquakes during sea-level fall and their delay during sea-level rise indicated by our model results may be recorded by sedimentary deposits in the forearc of subduction zones. For instance, at the southern Chilean active margin, turbidites were more frequent during glacial periods than during the Holocene and marine isotope stage (MIS) 5 (Blumberg et al., 2008). Under the assumption that the turbidites were mainly triggered by earthquakes, the authors infer that the recurrence interval of large subduction earthquakes was 100-200 years during glacial periods. In contrast, the turbidite recurrence time was substantially higher during MIS 5 and the Holocene. Although the increase in turbidite recurrence time appears to be mainly controlled by a decrease in sediment availability (Blumberg et al., 2008), the reduction in Coulomb stress changes induced by postglacial sea-level rise may also have contributed to the increase in turbidite recurrence time by delaying earthquakes on the plate interface.

In conclusion, our two-dimensional finite-element model shows that sea-level changes may be able to affect the deformation in the forearc and the state of stress along the seismogenic part of the plate interface. During sea-level fall, seismic slip of the plate interface may be promoted, whereas it may be delayed by a rising sea level. Future modelling will be needed to assess the order of magnitude of the displacement and stress changes induced by sea-level variations if viscoelastic deformation, additional loading by enhanced late-glacial sediment deposition as well as coseismic and interseismic deformation of the upper plate are taken into account. 
Acknowledgements. We thank Ralf Hetzel for critical comments on an earlier version of the manuscript and Holger Steffen for helpful discussion. We thank Iain Stewart and an anonymous referee for their positive reviews. Funding was provided by the German Research Foundation (DFG) within the framework of an Emmy-Noether fellowship granted to A. Hampel (grant HA 3473/2-1).

Special Issue: "Subduction zones"

Edited by: S. Buiter, F. Funiciello, and J. van Hunen

\section{References}

Adam, J., Kläschen, D., Kukowski, N., and Flüh, E.: Upward delamination of Cascadia Basin sediment infill with landward frontal accretion thrusting caused by rapid glacial age material flux, Tectonics, 23, TC3009, doi:10.1029/2002TC001475, 2004.

Bard, E., Hamelin, B., Fairbanks, R. G., and Zindler, A.: U-Th ages from mass spectrometry in corals from Barbados: sea level during the past 130000 years, Nature, 346, 456-458, 1990.

Blumberg, S., Lamy, F., Arz, H. W., Echtler, H. P., Wiedicke, M., Haug, G. H., and Oncken, O.: Turbiditic trench deposits at the South-Chilean active margin: A Pleistocene-Holocene record of climate and tectonics, Earth Planet. Sci. Lett., 268, 526-539, doi:10.1016/j.epsl.2008.02.007, 2008.

Bourgois, J., Guivel, C., Lagabrielle, Y., Calmus, T., Boulegue, J., and Daux, V.: Glacial-interglacial trench supply variation, spreading-ridge subduction, and feedback controls on the Andean margin development at the Chile triple junction area (45$48^{\circ}$ S), J. Geophys. Res., 105, 8355-8386, 2000.

Buiter, S. J. H., Govers, R., and Wortel, M. J. R.: A modelling study of vertical surface displacements at convergent plate margins, Geophys. J. Int. 147, 415-427, 2001.

Chappell, J. and Shackleton, N. J.: Oxygen isotopes and sea level, Nature 324, 137-140, 1986.

Church, M. and Slaymaker, O.: Disequilibrium of Holocene sediment yield in glaciated British Columbia, Nature, 337, 452-454, 1989.

Cochran, E. S., Vidale, J. E., and Tanaka, S.: Earth tides can trigger shallow thrust fault earthquakes, Science, 306, 1164-1166, 2004.

Cohen, S. C.: Does rapid change in ice loading modulate strain accumulation and release in glaciated, tectonically active regions? Geophys. Res. Lett., 20, 2123-2126, 1993.

Covault, J. A., Romans, B. W., Graham, S. A., Fildani, A., and Hilley, G. E.: Terrestrial source to deep-sea sink sediment budgets at high and low sea levels: Insights from tectonically active Southern California, Geology, 39, 619-622, doi:10.1130/G31801.1, 2011.

Hampel, A. and Pfiffner, A.: Relative importance of trenchward upper plate motion and friction along the plate interface for the topographic evolution of mountain belts, in: Analogue and Numerical Modelling of Crustal-Scale Processes, edited by: Buiter, S. J. H. and Schreurs, G., Geol. Soc. London Spec. Publ., 253, 105-115, 2006.
Hanks, T. C.: Earthquake stress drops, ambient tectonic stresses and stresses that drive plate motions, Pure Appl. Geophys., 115, 441-458, 1977.

Hebbeln, D., Lamy, F., Mohtadi, M., and Echtler, H.: Tracing the impact of glacial-interglacial climate variability on erosion of the southern Andes, Geology, 35, 2, 131-134, 2007.

Hyndman, R. D. and Wang, K.: The rupture zone of Cascadia great earthquakes from current deformation and the thermal regime, J. Geophys. Res., 100, B11, 22133-22154, 1995.

Imbrie, J., Hays, J. D., Martinson, D. G., Mcintyre, A., Mix, A. C., Morley, J. J., Pisias, N. G., Prell, W. L., and Shackleton, N. J.: The orbital theory of Pleistocene climate: Support from a revised chronology of the marine record, in: Milankovitch and Climate, Part 1, edited by: Berger, A. L., Imbrie, J., Hays, J., Kukla, G., and Saltzman, B., Reidel, Boston, 269-305, 1984.

Ivins, E. R. and James, T. S.: Bedrock response to Llanquihue Holocene and present-day glaciation in southernmost South America, Geophys. Res. Lett., 31, L-24613, doi:10.1029/2004GL021500, 2004.

Kanamori, H. and Anderson, D. L.: Theoretical basis of some empirical relations in seismology, Bull. Seismol. Soc. Am., 65, 1073-1095, 1975.

Kasahara, J.: Tides, earthquakes and volcanoes, Science, 297, 348349, 2004.

Luttrell, K. and Sandwell, D.: Ocean loading effects on stress at near shore plate boundary fault systems, J. Geophys. Res., 115, B08411, doi:10.1029/2009JB006541, 2010.

Nasu, N., Kishinouye, F., and Kodaira, T.: Recent seismic activities in the Idu Peninsula (Part I), Bull. Earthquake Res. Inst., Tokyo Imperial Univ., 9, 22-35, 1931.

Peltier, W. R. and Fairbanks, R. G.: Global glacial ice volume and Last Glacial Maximum duration from an extended Barbados sea level record, Quat. Sci. Rev., 25, 3322-3337, 2006.

Sauber, J. and Molnia, B. F.: Glacier ice mass fluctuations and fault instability in tectonically active Southern Alaska, Global Planet. Change., 42, 279-293, 2004.

Sauber, J. and Ruppert, N. A.: Rapid Ice Mass Loss: Does it have an influence on Earthquake Occurrence in Southern Alaska?, in: Active Tectonics and Seismic Potential of Alaska, edited by: Freymüller, J. T., Haeussler, P. J., Wesson, R. L., and Ekström, G., Geophys. Monograph Series, 179, 369-384, 2008.

Sauber, J., Plafker, G., Molnia, B. F., and Bryant, M. A.: Crustal deformation associated with glacial fluctuations in the eastern Chugach Mountains, Alaska, J. Geophys. Res., 105, 8055-8077, 2000.

Scholz, C. H.: The mechanics of earthquakes and faulting, Cambridge University Press, second edition, New York, 496 p., 2002.

Shlien, S.: Earthquake-tide correlation, Geophys. J. R. Astr. Soc., 28, 27-34, 1972.

Stern, R. J.: Subduction zones, Rev. Geophysics, 40, 1012, doi:10.1029/2001RG000108, 2002.

Tsuruoka, H., Ohtake, M., and Sato, H.: Statistical test of the tidal triggering of earthquakes: contribution of the ocean tide loading effect, Geophys. J. Int., 122, 183-194, 1995.

Zachos, J., Pagani, M., Sloan, L., Thomas, E., and Billups, K.: Trends, Rhythms, and Aberrations in Global Climate 65 Ma to Present, Science, 292, 686-693, 2001. 